\title{
VAZÃO DE GOTEJADORES APLICANDO ESGOTO SANITÁRIO TRATADO E PREVENÇÃO DO ENTUPIMENTO COM CATALISADOR ENZIMÁTICO'
}

\author{
Ketson Bruno da Silva* \\ Rafael Oliveira Batista** \\ Daniela da Costa Leite Coelho*** \\ Blake Charles Diniz Marques ${ }^{* * * * *}$ \\ Francisco de Oliveira Mesquita****** \\ Jorge Luiz de Oliveira Cunha $a^{\text {sssses }}$
}

RESUMO: O reúso da água é uma importante ação da gestão integrada dos recursos hídricos que possibilita a convivência com a escassez hídrica no semiárido brasileiro. O sistema de irrigação por gotejamento é o mais adequado para aplicação de esgoto sanitário tratado, entretanto o entupimento de emissores consiste no principal obstáculo à adoção desta tecnologia. Neste sentido, este trabalho objetivou estudar a vazão de gotejadores operando com esgoto sanitário tratado, bem como a prevenção da obstrução por meio do uso de catalisador enzimático. Para isto, foram montadas duas bancadas experimentais para avaliação, a cada 80 h, da vazão de quatro tipos de gotejadores, aplicando esgoto sanitário tratado durante $400 \mathrm{~h}$. O experimento foi montado em esquema de parcelas subsubdivididas, no delineamento inteiramente casualizado (DIC) com três repetições. Tendo nas parcelas as dosagens de catalisador enzimático (T1 - unidade gotejadora que operou sem aplicação do catalisador; T2 - unidade gotejadora que recebeu $100 \mathrm{ml}$ de catalisador, a cada $80 \mathrm{~h}$; T3 - unidade gotejadora que recebeu $200 \mathrm{ml}$ de catalisador, a cada $80 \mathrm{~h}$; e T4 - unidade gotejadora

1 Este trabalho é parte da tese de doutorado do primeiro autor.

* Doutor em Manejo de Solo e Água, pela Universidade Federal Rural do Semi-Árido (UFERSA), Brasil. E-mail: ketsonbruno@hotmail.com

** Doutorado em Engenharia Agrícola pela Universidade Federal de Viçosa (UFV). Docente Adjunto IV da Universidade Federal Rural do Semi Árido (UFERSA) e Docente permanente do Programa de Pós-Graduação em Manejo de Solo e Água da UFERSA, Brasil.

*** Doutora em Manejo de Solo e Água pelo Programa de Pós-Graduação em Manejo de Solo e Água na Universidade Federal Rural do Semi Árido (UFERSA), Brasil.

***** Docente adjunto I do curso de Engenharia de Produção na Universidade Federal Rural do Semi-Árido (UFERSA), Brasil.

****** Doutorado pelo Programa de Pós-Graduação em Manejo de Solo e Água, Universidade Federal Rural do Semi-Árido (UFERSA), Brasil.

******* Doutorando no Programa de Pós-Graduação em Manejo de Solo e Água Universidade Federal Rural do Semi Árido (UFERSA). Pró-Reitor de Administração da UFERSA, Brasil. 
que recebeu $300 \mathrm{ml}$ de catalisador, a cada $80 \mathrm{~h}$, nas subparcelas os tipos de gotejadores (Netafim Super Typhoon, Netafim Tiran, Netafim Streamline e Naan Dan Jain Tal Drip) e nas subsubparcelas os períodos das avaliações da vazão dos gotejadores $(0,80,160,240,320$ e 400 h). O catalisador enzimático não preveniu a obstrução dos gotejadores em função da elevada concentração de cloreto no esgoto sanitário tratado. Os modelos de regressão cúbico, quadrático e linear foram os que melhor se ajustaram aos dados de vazão em função dos tempos de operação mediante tratamento biológico. As análises de regressão linear múltipla revelaram que os atributos SD, SS e $\mathrm{pH}$ foram os que mais interferiram no processo de entupimento dos gotejadores aplicando esgoto sanitário tratado.

PALAVRAS-CHAVE: Modelos empíricos; Obstrução; Reúso.

\section{DISCHARGE OF DRIPPERS WITH TREATED SANITARY SLUDGE AND THE PREVENTION OF CLOGGING WITH ENZYMATIC CATALYZER}

ABSTRACT: Water reuse is an important management activity integrated with water resources that makes possible conviviality with hydric scarcity in the Brazilian semidesert region. The drip irrigation system is highly adequate for the application of treated sanitary sludge, although drip clogging may be the main obstacle for the adoption of the technology. Current study analyzes the discharge of drips with treated sanitary sludge and the prevention of obstruction by enzymatic catalyzer. Two assay benches were prepared for the evaluation, at every $80 \mathrm{~h}$, of discharge of four drip types, applying sanitary sludge treated during $400 \mathrm{~h}$. Assay was prepared in a totally randomized sub-sub-plot scheme, with three replications, with doses of enzymatic catalyzer as follows: T1 - drip unit without the application of catalyzer; T2 - drip unit with $100 \mathrm{ml}$ of catalyzer every $80 \mathrm{~h}$; T3 - drip unit with $200 \mathrm{ml}$ catalyzer every $80 \mathrm{~h}$; and T4 - drip unit with $300 \mathrm{ml}$ catalyzer every $80 \mathrm{~h}$; sub-plots had the following drip types (Netafim Super Typhoon, Netafim Tiran, Netafim Streamline and Naan Dan Jain Tal Drip); in sub-sub-plot the periods of evaluation for drip charge were $(0,80,160,240,320$ and $400 \mathrm{~h})$. Enzymatic catalyzer failed to avoid drip obstruction due to the high concentration of chloride in the treated sanitary sludge. Cubic, quadratic and linear regression models were the best for discharge data due to operation time through biological treatment. Multiple linear regression analyses revealed that attributes SD, SS and $\mathrm{pH}$ greatly interfered in the clogging process of drips with treated sanitary sludge.

KEY WORDS: Empirical models; Obstruction; Reuse. 


\section{INTRODUÇÃO}

Nas regiões áridas e semiáridas tanto a inadequação dos sistemas de esgotamento sanitário quanto a escassez hídrica são problemas que comprometem a qualidade de vida da população. No entanto, o uso agrícola dos esgotos sanitários devidamente tratados surge como alternativa para a mitigação desses dois problemas (JASIM et al., 2016).

Os sistemas de irrigação por gotejamento se destacam para aplicação de água residuária em detrimento da maior eficiência no uso da água e dos nutrientes e da minimização dos riscos ambientais, devido a não geração de aerossóis que possam ser transportados pelo vento (SONG et al., 2017). Todavia, o entupimento de gotejadores tornou-se um dos principais obstáculos quanto ao uso da irrigação por gotejamento para aplicação de esgotos sanitários tratados (ZHOU et al., 2017).

O principal agente de obstrução de gotejadores que operam com esgoto sanitário tratado é o biofilme gerado pela combinação de partículas orgânicas e inorgânicas, mucilagens bacterianas e precipitados químicos (ZHOU et al., 2017).

O entupimento dos gotejadores de um sistema de irrigação por gotejamento resulta na alteração da vazão de projeto em virtude do entupimento parcial ou total dos emissores, comprometendo a uniformidade de aplicação do efluente e consequentemente a eficiência do sistema de irrigação (FERNANDES et al., 2014; MARQUES et al., 2016; MESQUITA et al., 2016a; b; SIIVA et al., 2016; CUNHA et al., 2017).

Entre as tecnologias existentes para a desobstrução de gotejadores, que não utilizam produtos químicos e nem geram subprodutos tóxicos, se destacam o tratamento biológico com bactérias degradadoras de biofilme impulsionadas pelo uso de catalisador enzimático (COSTA et al., 2016) e o aumento da pressão de serviço na malha hidráulica do sistema de irrigação por gotejamento (SILVA et al., 2016; BATISTA et al., 2018) para minimizar a adesão de biofilme no interior dos emissores e das linhas laterais.

No trabalho de Costa et al. (2016) gotejadores obstruídos por biofilme, oriundo de $400 \mathrm{~h}$ de aplicação de esgoto sanitário tratado, apresentaram recuperação significativa da vazão com apenas uma aplicação de solução biológica (bactérias 
degradadoras de biofilme mais catalisador enzimático) e tempo de permanência no interior das linhas laterais de $48 \mathrm{~h}$.

Os resultados apresentados por Silva et al. (2016) e Batista et al. (2018) evidenciaram que o aumento na pressão de serviço de unidades gotejadoras abastecidas com água residuária do processamento da castanha de caju minimiza o entupimento de gotejadores, bem como os problemas de desuniformidade de aplicação de efluente. Nestes trabalhos é relatado que a pressão de serviço de $140 \mathrm{KPa}$ foi a mais adequada dentre as ensaiadas para mitigar a obstrução dos emissores.

Diante do exposto, o presente trabalho teve como objetivo estudar o comportamento da vazão de unidades gotejadoras operando com esgoto sanitário tratado e recebendo a cada 80 h, durante 400 h, solução contendo catalisador enzimático para prevenir o entupimento dos gotejadores com biofilme.

\section{MATERIAL E MÉTODOS}

O presente trabalho foi realizado no período de julho a outubro de 2015, na área experimental no campus Leste da Universidade Federal Rural do Semi-Árido (UFERSA)

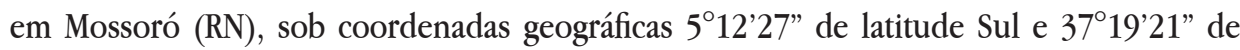
longitude Oeste.

O município de Mossoró possui altitude de 40,5 m e está localizado somente a $40 \mathrm{~km}$ do Atlântico Norte. O clima da região, segundo a classificação de Köppen, é do tipo BSwh, sendo um clima seco, muito quente e com estação chuvosa no verão atrasando-se para o outono, com uma precipitação pluviométrica bastante irregular, com média anual de $673,9 \mathrm{~mm}$; a temperatura média de $27^{\circ} \mathrm{C}$ e umidade relativa do ar média de $68,9 \%$ (ALVARES et al., 2013).

A água residuária de origem doméstica foi coletada na Estação de Tratamento de Efluentes (ETE) de Mossoró (RN), gerenciada pela empresa Imunizadora Oeste Ltda. De acordo com Costa et al. (2016), esta ETE compreende as etapas de tratamento preliminar, tratamento secundário e tratamento terciário. O tratamento preliminar é composto por grade e desarenador; já o tratamento secundário inclui as lagoas anaeróbia e facultativa; e o tratamento terciário compreende as lagoas de maturação. A estação recebe, em média, 60 $\mathrm{m}^{3}$ de esgoto sanitário por dia.

A coleta do efluente foi realizada, diretamente, da lagoa de maturação da ETE, 
utilizando-se caminhão tanque com capacidade para $7 \mathrm{~m}^{3}$, que recalcava o efluente com motobomba própria. Na UFERSA, o efluente foi armazenado em dois reservatórios, um com capacidade armazenadora de $5 \mathrm{~m}^{3}$, e outro de $1 \mathrm{~m}^{3}$. O reabastecimento do reservatório repetia-se a cada vez que havia perdas de água por evaporação.

Para a realização dos ensaios foram montadas duas bancadas experimentais de constituições e dimensões iguais, como apresentado na Figura 1. Cada estrutura consistia de uma base de madeira, na qual serviram de sustentação para telhas de fibrocimento onduladas.

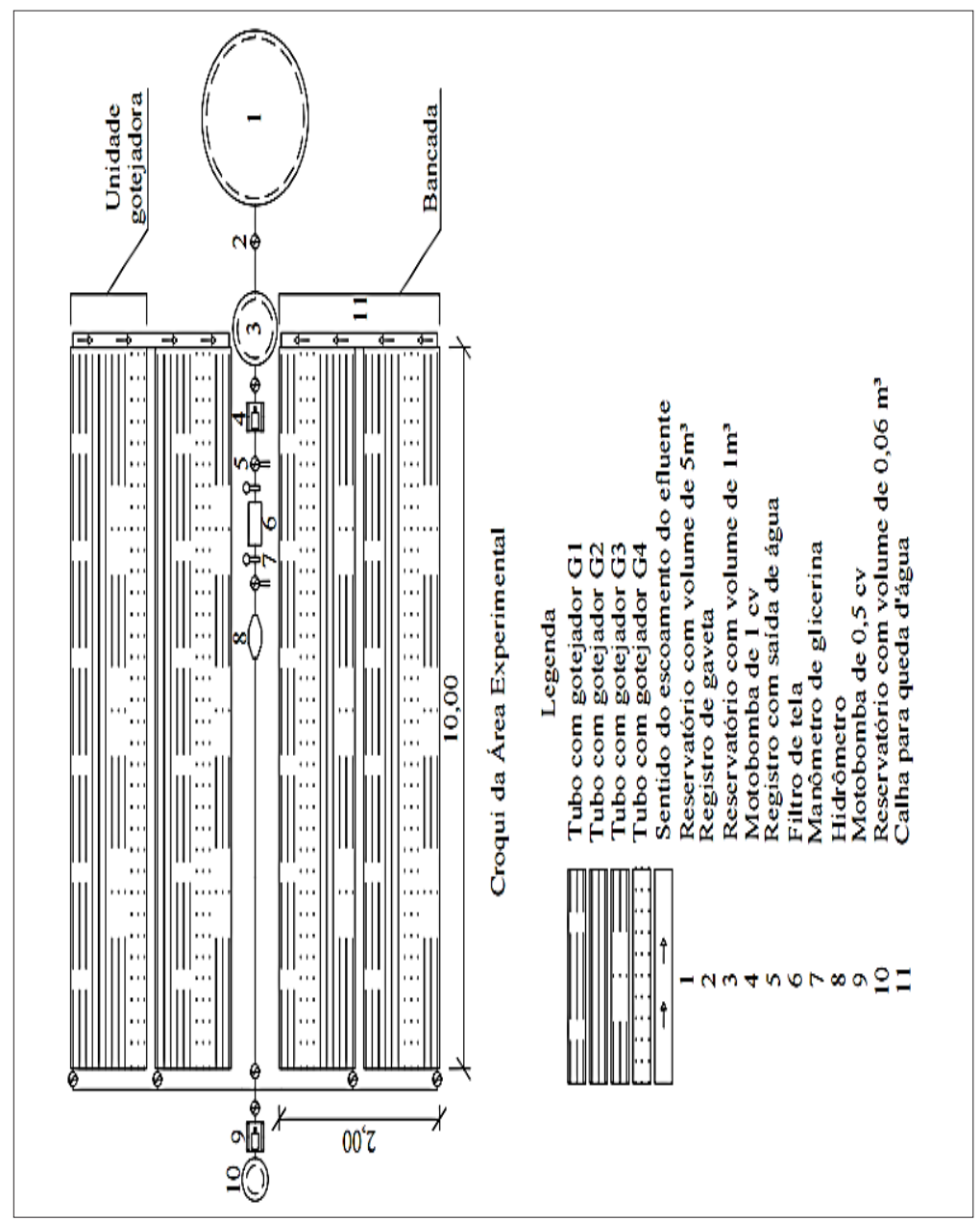

Figura 1. Croqui da área experimental destacando as duas bancadas, as unidades gotejadoras, os reservatórios e o sistema de injeção do catalisador enzimático. 
Cada bancada apresentou $2 \mathrm{~m}$ de largura por $10 \mathrm{~m}$ de comprimento, resultando em área superficial de $20 \mathrm{~m}^{2}$, possuindo uma declividade vertical de $2 \%$. Uma canaleta adaptada com tubo PVC de $100 \mathrm{~mm}$ de diâmetro nominal foi instalada após o final da extremidade mais baixa da bancada, com sentido direcionado até o reservatório de armazenamento de $1 \mathrm{~m}^{3}$, para recirculação do efluente.

No interior de cada bancada experimental foram montadas duas unidades gotejadoras que operaram com esgoto doméstico tratado. A bancada foi composta por um conjunto motobomba de $1 \mathrm{cv}$, para recalque do esgoto sanitário tratado, um conjunto motobomba $0,5 \mathrm{cv}$ para injeção da solução enzimática na malha hidráulica das unidades gotejadoras, um filtro de tela com abertura de $130 \mu \mathrm{m}$ e um hidrômetro com capacidade para $1,5 \mathrm{~m}^{3} \mathrm{~h}^{-1}$, conforme apresentado na Figura 1 . Enfim as duas bancadas experimentais foram compostas por quatro unidades gotejadoras que operaram com esgoto sanitário tratado.

Foram instalados dois manômetros analógicos de glicerina, marca GE CI 2.5 , graduado de 0 a $400 \mathrm{kPa}$, para visualização e regulagem de pressão antes e após o filtro de tela.

Cada unidade gotejadora apresentava um registro de gaveta, uma linha de derivação de PVC com diâmetro nominal de $32 \mathrm{~mm}$ com doze conectores, para inserção de doze linhas laterais de polietileno com dez metros de comprimento, totalizando 24 linhas laterais em cada bancada.

Em cada unidade gotejadora foram ensaiados quatro tipos de gotejadores, sendo suas características obtidas de catálogos técnicos fornecidos pelos fabricantes e medidas com o auxílio de paquímetro, conforme apresentadas na Tabela 1. 
Tabela 1. Gotejadores $(\mathrm{G})$ utilizados nos ensaios experimentais, destacando o fabricante (F), o dispositivo de autocompensação (DA), a vazão nominal $(\mathrm{Q})$, o coeficiente de vazão $(\mathrm{k})$, expoente da vazão que caracteriza o regime de escoamento (x), a área de filtragem (A), o comprimento do labirinto $(\mathrm{L})$, a faixa de pressão recomendada $(\mathrm{P})$ e o espaçamento entre emissores (EE)

\begin{tabular}{cccccccccc}
\hline $\mathbf{G}$ & \multicolumn{1}{c}{$\mathbf{F}$} & $\mathbf{D A}^{*}$ & $\begin{array}{c}\mathbf{Q}^{1 *} \\
\left(\mathbf{L ~ h}^{-1}\right)\end{array}$ & $\mathbf{k}^{*}$ & $\mathbf{x}^{*}$ & $\begin{array}{c}\mathbf{A}^{*} \\
\left(\mathbf{m m}^{2}\right)\end{array}$ & $\begin{array}{c}\mathbf{L}^{*} \\
(\mathbf{m m})\end{array}$ & $\begin{array}{c}\mathbf{P}^{*} \\
(\mathbf{k P a})\end{array}$ & $\begin{array}{c}\mathbf{E E}^{*} \\
(\mathbf{m})\end{array}$ \\
\hline G1 & $\begin{array}{l}\text { Netafim Super } \\
\text { Typhoon }\end{array}$ & Não & 1,60 & 0,53 & 0,48 & 34,0 & 23 & $60-100$ & 0,30 \\
G2 & Netafim Tiran & Não & 2,00 & 0,69 & 0,46 & 70,0 & 75 & $100-300$ & 0,40 \\
G3 & $\begin{array}{l}\text { Netafim } \\
\text { Streamline }\end{array}$ & Não & 1,60 & 0,57 & 0,45 & 17,0 & 13 & $65-100$ & 0,30 \\
G4 & $\begin{array}{l}\text { Naan Dan Jain } \\
\text { Tal Drip }\end{array}$ & Não & 1,70 & 0,56 & 0,46 & $6,0^{* *}$ & $44^{* *}$ & $50-00$ & 0,20 \\
\hline
\end{tabular}

Nota: ${ }^{1}$ Vazão nominal dos gotejadores na pressão de serviço de $100 \mathrm{kPa} ;{ }^{*}$ Informações obtidas nos catálogos dos fabricantes. PCJ - Este mantém uma vazão uniforme mesmo sob diferentes pressões de entrada, assegurando uma distribuição exata da água e nutrientes, além disto, o emissor possui amplas seções de passagem da água e constante atuação do mecanismo de auto-limpeza, que aumentam a sua resistência ao entupimento. CNJ - Sistema anti-drenante; e ** Informações obtidas com auxílio de um paquímetro digital, tendo precisão de $0,01 \mathrm{~mm}$.

$\mathrm{Na}$ realização do experimento as unidades gotejadoras funcionaram, em média, oito horas por dia até completar o tempo de funcionamento de $400 \mathrm{~h}$, para potencializar a formação do biofilme nos gotejadores e nas linhas laterais. Neste período, efetuaram-se seis avaliações do desempenho hidráulico das unidades gotejadoras operando com esgoto sanitário doméstico, especificamente nos tempos de operação de $0,80,160,240,320$ e $400 \mathrm{~h}$.

A vazão $(Q)$ dos gotejadores foi o indicador de desempenho hidráulico utilizado na detecção dos níveis de obstrução nas unidades gotejadoras, a qual foi determinada em dezesseis posições equidistantes de todas as linhas laterais. Os dados de Q foram obtidos coletando-se o volume aplicado pelo emissor, durante um período de três minutos. Foi obtido o cálculo de Q empregando-se a Equação 1. 


$$
\mathrm{Q}=\frac{\mathrm{V}}{1000 \cdot \mathrm{t}} \cdot 60
$$

Em que:

$\mathrm{Q}$ - vazão de cada gotejador, $\mathrm{L} \mathrm{h}^{-1}$;

$\mathrm{V}$ - volume coletado, $\mathrm{ml}$; e

$\mathrm{t}$ - tempo de coleta do efluente, min.

A pressão de serviço foi mantida no valor de $100 \mathrm{kPa}$, para obter os valores de vazões nominais nos gotejadores ensaiados. Deve ressaltar que não houve precipitação pluviométrica no período estudado.

A cada $80 \mathrm{~h}$ de operação das unidades gotejadoras, foram retiradas amostras do esgoto sanitário tratado para realização das análises físicas, químicas e microbiológicas, as quais foram analisadas com base no Standard Methods for the Examination of Water and Wastewater (RICE et al., 2012). As características obtidas destas amostras estão apresentadas na Tabela 2.

Tabela 2. Variação das características físicas, químicas e microbiológicas do esgoto sanitário tratado, ao longo do tempo de operação das unidades gotejadoras

\begin{tabular}{lcccccc}
\hline \multirow{2}{*}{ Características } & \multicolumn{7}{c}{ Tempo de operação } \\
\cline { 2 - 7 } & $\mathbf{0}$ & $\mathbf{8 0}$ & $\mathbf{1 6 0}$ & $\mathbf{2 4 0}$ & $\mathbf{3 2 0}$ & $\mathbf{4 0 0}$ \\
\hline $\mathrm{pH}$ & 8,63 & 8,49 & 8,90 & 8,27 & 8,67 & 8,75 \\
$\mathrm{CE}$ & 3,87 & 4,15 & 4,84 & 4,57 & 4,94 & 5,02 \\
$\mathrm{SS}$ & 440 & 460 & 600 & 540 & 660 & 680 \\
$\mathrm{SD}$ & 2225 & 2504 & 3204 & 2972 & 3172 & 3772 \\
$\mathrm{Ca}^{2+}$ & 1,62 & 2,30 & 1,70 & 1,30 & 1,30 & 1,50 \\
$\mathrm{Mg}^{2+}$ & 1,40 & 1,20 & 0,60 & 1,30 & 3,00 & 3,30 \\
$\mathrm{Cl}$ & 32,30 & 37,40 & 27,60 & 32,60 & 24,00 & 24,20 \\
$\mathrm{Mn}$ & 0,070 & 0,056 & 0,048 & 0,041 & 0,057 & 0,044 \\
$\mathrm{Fe}$ & 0,259 & 0,161 & 0,214 & 0,198 & 0,305 & 0,342 \\
$\mathrm{CT}$ & $2,6 \times 10^{3}$ & $1,2 \times 10^{3}$ & $1,0 \times 10^{3}$ & $6,0 \times 10^{2}$ & $2,0 \times 10^{2}$ & $2,0 \times 10^{2}$ \\
\hline
\end{tabular}

Nota: $\mathrm{pH}$ - Potencial hidrogeniônico; CE - Condutividade elétrica, dS $\mathrm{m}^{-1} ;$ SS - Sólidos suspensos, $\mathrm{mg}$ $\mathrm{I}^{-1} ; \mathrm{SD}$ - Sólidos dissolvidos, $\mathrm{mg} \mathrm{l}^{-1} ; \mathrm{Ca}^{2+}$ - Cálcio, $\mathrm{mmol}_{\mathrm{c}} \mathrm{L}^{-1} ; \mathrm{Mg}^{2+}$ - Magnésio, mmol $\mathrm{L}^{-1} ; \mathrm{Cl}^{-}$- Cloreto, mmol $\mathrm{L}^{-1} ; \mathrm{Mn}$ - Manganês total, $\mathrm{mg} \mathrm{l}^{-1} ; \mathrm{Fe}$ - Ferro total, $\mathrm{mg} \mathrm{L}^{-1}$; CT - Coliformes Totais, UFC $100 \mathrm{ml}^{-1} ; \mathrm{e}$ UFC - Unidades Formadoras de Colônias. 
Para prevenir a obstrução dos gotejadores, foi utilizado com auxílio de uma proveta, um produto a base das enzimas amilase, protease, lipase, pectinase e celulase, que catalisam as reações de biodegradação das substâncias orgânicas, promovendo a quebra (desdobra) das moléculas orgânicas, transformando-as em frações menores originando matéria orgânica decomposta. De acordo com o fabricante, é indicado para o tratamento de águas que possuem suas características naturais alteradas por dejetos humanos ou animais, com altas cargas de matéria orgânica e mineral, em solução e em suspensão, assim como elevados níveis populacionais de bactérias e outros organismos patogênicos e não patogênicos.

O catalisador foi aplicado a cada $80 \mathrm{~h}$ de operação das quatro unidades gotejadoras. Para isso, foi realizada uma adaptação na bancada experimental inserindo um sistema de injeção de solução, composto por um conjunto motobomba de $0,5 \mathrm{cv}$ e um depósito plástico com capacidade de $0,060 \mathrm{~m}^{3}$, para armazenar a solução com o catalisador enzimático.

Foram realizadas ao todo cinco aplicações, sendo a primeira feita após 80 $\mathrm{h}$ de funcionamento do sistema, a segunda após 160 h, a terceira após $240 \mathrm{~h}$, a quarta após $320 \mathrm{~h}$ e a quinta após $400 \mathrm{~h}$. Os tratamentos consistiam na dose do produto, medido com o auxílio de uma proveta, e misturado em $0,050 \mathrm{~m}^{3}$ de água de abastecimento público. Após a inserção de ambos dentro do reservatório, a calda foi homogeneizada com auxílio de uma barra de vidro. Estas dosagens estavam dentro de uma margem que obedecia às recomendações do fabricante, sendo divididas da seguinte maneira:

- Tratamento 1 (TRAT 1): unidade gotejadora que operou sem aplicação do catalisador enzimático.

- Tratamento 2 (TRAT 2): unidade gotejadora que recebeu a cada 80 h, 100 $\mathrm{ml}$ do catalisador enzimático diluído em $0,050 \mathrm{~m}^{3}$ de água de abastecimento público.

- Tratamento 3 (TRAT 3): unidade gotejadora que recebeu a cada 80 h, 200 $\mathrm{ml}$ do catalisador enzimático diluído em $0,050 \mathrm{~m}^{3}$ de água de abastecimento público.

- Tratamento 4 (TRAT 4): unidade gotejadora que recebeu a cada 80 h, 300 $\mathrm{ml}$ do catalisador enzimático diluído em $0,050 \mathrm{~m}^{3}$ de água de abastecimento público. 
À medida que uma unidade gotejadora recebida a dosagem do produto, as outras três tinham seus registros de gavetas fechados, para não receberem outras dosagens. Após cada aplicação do produto, deixava-se o sistema inativo por $48 \mathrm{~h}$ para possibilitar a ação adequada do produto. Ocorrido isto, imediatamente as unidades gotejadoras foram submetidas à avaliação do desempenho hidráulico determinandose a vazão dos gotejadores.

$\mathrm{O}$ experimento foi montado em esquema de parcelas subsubdivididas, tendo nas parcelas os tratamentos T1, T2, T3 e T4, nas subparcelas os tipos de gotejadores (G1, G2, G3 e G4) e nas subsubparcelas os períodos das avaliações ( 0 , $80,160,240,320$ e $400 \mathrm{~h})$.

Os dados foram submetidos à análise de variância (ANOVA) empregando-se o teste $\mathrm{F}$ a $5 \%$ de probabilidade. Os valores dos coeficientes de variação das parcelas, subparcelas e subsubparcelas foram classificados pelos critérios propostos por Pimentel-Gomes (2019), que classifica os coeficientes de variação da seguinte forma: baixo quando inferior a 10\%; médio, entre 10 e $20 \%$; alto, quando estão entre 20 e $30 \%$; e muito alto, quando superior a $30 \%$.

Os modelos de regressão simples e múltipla foram escolhidos com base na significância dos coeficientes de regressão, aplicando-se o teste t em um nível de até $10 \%$, no coeficiente de determinação $(\geq 60 \%)$ e no processo em estudo.

Nas análises estatísticas dos dados utilizou-se o programa computacional Sistema para Análises Estatísticas Versão 9.1 (RIBEIRO JÚNIOR; MELO, 2008).

\section{RESULTADOS E DISCUSSÕES}

$\mathrm{Na}$ Tabela 3 encontra-se o resumo das análises de variância obtidas da variável vazão $(\mathrm{Q})$ das unidades gotejadoras, que operaram com esgoto sanitário tratado, durante $400 \mathrm{~h}$, mediante tratamento biológico com catalisador enzimático. Verificouse que a interação tripla (TRAT x G x T) foi significativa a $1 \%$ de probabilidade pelo teste $\mathrm{F}$, indicando que existe efeito dos fatores TRAT, G e T na alteração da vazão dos emissores das unidades gotejadoras que operaram com esgoto doméstico tratado. Todas as interações duplas (TRAT x G, TRAT x T e G x T) também foram significativas a $1 \%$ de probabilidade. Em relação aos fatores isolados notou-se que $\mathrm{T}$ e $\mathrm{G}$ foram 
significativos a $1 \%$ de probabilidade, enquanto TRAT não foi significativo a $5 \%$ de probabilidade, indicando que isoladamente o tratamento biológico não alterou significativamente a vazão dos emissores das unidades gotejadoras. Estes resultados diferem dos encontrados por Costa et al. (2016) que utilizaram o tratamento biológico na recuperação da vazão de gotejadores que operaram durante $400 \mathrm{~h}$ com esgoto sanitário tratado, onde a interação tripla (DOSES DO PRODUTO x TRATAMENTOS APLICADOS x TIPOS DE GOTEJADORES) não foi significativa a $5 \%$ de probabilidade para a variável vazão dos emissores. $\mathrm{O}$ entupimento dos gotejadores exerceu maior interferência nos fatores $\mathrm{G}$ e T isolados e nas suas interações, entretanto as dosagens de catalisador enzimático não resultaram em boa prevenção do entupimento dos gotejadores.

Tabela 3. Resumo da análise de variância da variável vazão $(\mathrm{Q})$ no esquema de parcelas subsubdivididas

\begin{tabular}{lcc}
\hline \multirow{2}{*}{ Fontes de variação } & Graus de liberdade & Quadrado médio \\
\cline { 3 - 3 } & 3 & $\mathbf{Q}$ \\
\hline Tratamentos (TRAT) & 6 & $0,0092^{\text {ns }}$ \\
\hline Resíduo (a) & 3 & 0,02 \\
\hline Tipos de gotejadores (G) & 9 & $0,46^{* *}$ \\
TRAT x G & 24 & $0,04^{* * *}$ \\
\hline Resíduo (b) & 5 & 0,01 \\
\hline Tempo de funcionamento (T) & 15 & $5,65^{* *}$ \\
TRAT x T & 15 & $0,07^{* *}$ \\
G x T & 45 & $0,11^{* *}$ \\
TRAT x G x T & 162 & $0,02^{* * *}$ \\
\hline Resíduo (c) & & 0,01 \\
\hline CV (\%) parcela & & 11,69 \\
CV (\%) subparcela & & 10,26 \\
CV (\%) subsubparcela & & 8,63
\end{tabular}

Nota: $Q$ - vazão; CV - coeficiente de variação; * Significativo a $1 \%$ de probabilidade pelo teste $F ;{ }^{\text {ns }}$ Não significativo a $5 \%$ de probabilidade pelo teste $\mathrm{F}$.

Segundo Pimentel-Gomes (2009), os valores dos coeficientes de variação das parcelas e subparcelas foram classificados como médio $(10 \%<$ coeficiente de variação < 20\%), enquanto o coeficiente de variação da subsubparcela foi classificado 
como baixo $(<10 \%)$, indicando boa precisão na coleta dos dados de vazão dos emissores. Os coeficientes de variação das parcelas, subparcelas e subsubparcelas do presente estudo foram ligeiramente superiores aos valores do trabalho de Costa et al. (2016) que utilizaram o tratamento biológico para recuperar a vazão de gotejadores obstruídos por agentes biológicos, físicos e químicos oriundos de $400 \mathrm{~h}$ de aplicação de esgoto sanitário tratado.

Na Figura 2 estão apresentados os valores da vazão dos gotejadores G1 e G2, ao longo das $400 \mathrm{~h}$ de aplicação de esgoto sanitário tratado pelas unidades gotejadoras, mediante aplicação de dosagens de catalizador enzimático, a cada $80 \mathrm{~h}$.

A.

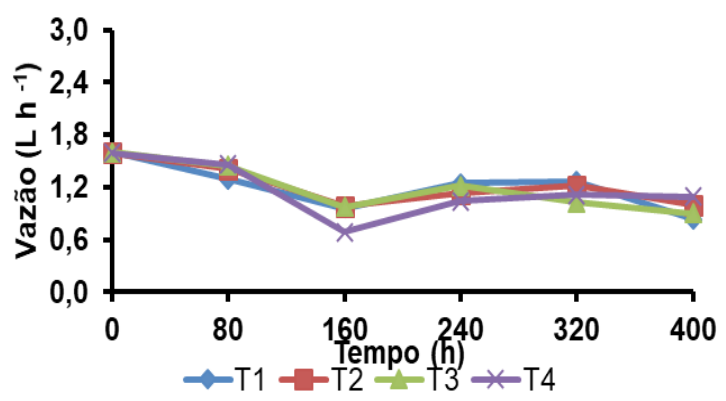

B.

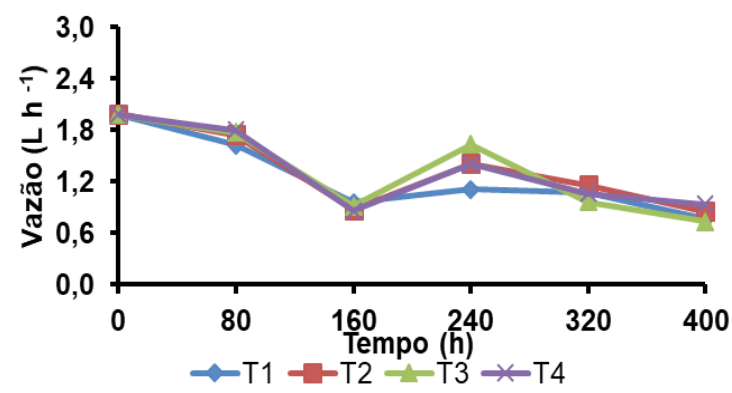

Figura 2. Comportamento da vazão dos emissores G1 (A) e G2 (B), ao longo do período de operação, mediante aplicação das dosagens de catalizador enzimático (T). 
Estabelecendo comparação entre os tempos de operação inicial $(0 \mathrm{~h})$ e final (400 h) da Figura 2, evidenciou-se que a vazão dos emissores G1 e G2 reduziu, em função da obstrução com biofilme resultante da interação entres agentes físico-químicos e microbiológicos provenientes do esgoto sanitário tratado, independentemente da dosagem de catalizador enzimático utilizada.

Constataram-se, ao longo ao período experimental, oscilações dos valores da vazão dos gotejadores G1 e G2 em todos os tratamentos. Notou-se que todos os valores de vazão decrescem até o tempo de operação de 160 h, a partir daí os valores de vazão aumentam e diminuem até as $400 \mathrm{~h}$. Este fato é atribuído ao processo de desobstrução aleatório ocasionado pela movimentação brusca das linhas laterais nos momentos da avaliação do desempenho hidráulico, que acarreta o desprendimento de biofilme dos emissores, conforme retratado por Cunha et al. (2017).

Após $400 \mathrm{~h}$ de operação das unidades gotejadoras houve redução na vazão dos emissores G1 e G2 de 48 e 61\%, 37 e 57\%, 44 e 63\% e 31 e 53\% para os tratamentos T1, T2, T3 e T4, respectivamente. Essas reduções de vazão foram superiores os valores de 8, 31, 14 e 7\% obtidos por Marques et al. (2016) com os mesmos emissores G1, G2, G3 e G4 do presente estudo operando com efluente de laticínios diluído durante $200 \mathrm{~h}$.

Comparando os dois tipos de emissores percebeu-se maior suscetibilidade ao entupimento em G2, devido ao seu maior comprimento de labirinto (Tabela 1), que favorece a sedimentação de material particulado, bem como o desenvolvimento de biofilme nos trechos de menor velocidade de escoamento do efluente deste emissor (BATISTA et al., 2013).

Mesmo com o uso do catalisador enzimático as reduções de vazão foram elevadas e com valores próximos do tratamento controle (T1), confrontando os resultados obtidos por Costa et al. (2016) que utilizaram o tratamento biológico na recuperação da vazão de gotejadores.

Constam na Figura 3 os valores da vazão dos gotejadores G3 e G4, ao longo das $400 \mathrm{~h}$ de aplicação de esgoto sanitário tratado pelas unidades gotejadoras, mediante aplicação de dosagens de catalizador enzimático, a cada 80 h. Constatouse também, ao longo do período experimental, redução da vazão dos emissores G3 e G4 de todas as unidades gotejadoras submetidas às dosagens de catalizador enzimático. 
A.

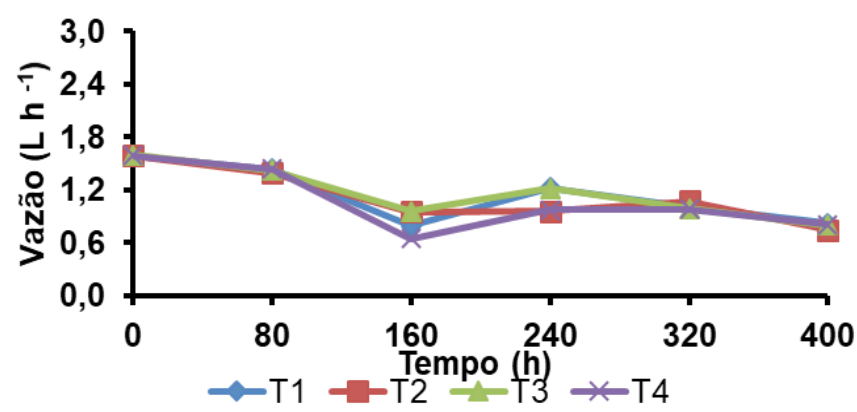

B.

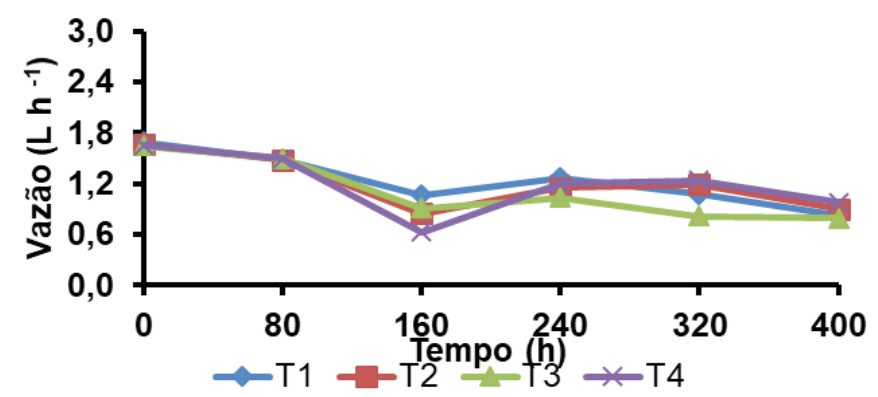

Figura 3. Comportamento da vazão dos emissores G3 (A) e G4 (B), ao longo do período de operação, mediante aplicação das dosagens de catalizador enzimático (T).

Após $160 \mathrm{~h}$ de operação também ocorreu o processo de desobstrução aleatório retratado por Cunha et al. (2017) nas unidades gotejadoras dotadas dos emissores G3 e G4.

Ao comparar os tempos de operação inicial $(0 \mathrm{~h})$ e final $(400 \mathrm{~h})$ constatouse redução nos valores da vazão dos emissores G3 e G4 de 48 e 51\%, 53 e 45\%, 50 e $52 \%$ e 49 e $41 \%$ para os tratamentos T1, T2, T3 e T4, respectivamente, indicando níveis de obstrução semelhantes entre esses dois tipos de emissores. Essas reduções de vazão diferem da faixa de 6 a 42\% encontrada por Fernandes et al. (2014) em unidades gotejadoras que operaram por $160 \mathrm{~h}$ com efluente do processamento da castanha de caju.

Confrontando as reduções de vazão das unidades gotejadoras que receberam a aplicação do catalizador enzimático (T2, T3 e T4) com a da unidade 
gotejadora controle (T1) evidenciou-se que o tratamento biológico não preveniu satisfatoriamente o processo de obstrução por biofilme também nos emissores G3 e G4.

A ineficácia do catalisador enzimático na prevenção do entupimento dos gotejadores é atribuída à elevada concentração de cloreto no esgoto sanitário tratado (Tabela 2) que provavelmente inibiu as atividades bacterianas durante o período experimental. Isto é, o cloreto já havia afetado os microrganismos que poderiam ter sido inativados pelo catalisador enzimático.

$\mathrm{Na}$ Tabela 4, encontram-se as equações de regressão ajustadas à vazão (Q), em função dos tempos de operação das unidades gotejadoras submetidas aos tratamentos biológicos para a prevenção do entupimento.

Tabela 4. Equações de regressão ajustadas a vazão (Q) em função dos tempos de operação (T) das unidades gotejadoras, para os quatro tipos de emissores (G1, G2, G3 e G4) e os quatro tratamentos biológicos para a prevenção do entupimento (T1, T2, T3 e T4)

\begin{tabular}{llll}
\hline TRAT & G & Equações de regressão & $\mathbf{R}^{2}$ \\
\hline 1 & 1 & $\hat{\mathrm{Q}}=1,634-0,00987^{* *} \cdot \mathrm{T}+0,000055^{* *} \cdot \mathrm{T}^{2}-0,0000000881^{* *} \cdot \mathrm{T}^{3}$ & 0,71 \\
1 & 2 & $\hat{\mathrm{Q}}=1,961-0,0058^{* *} \cdot \mathrm{T}+0,00000772^{* *} \cdot \mathrm{T}^{2}$ & 0,82 \\
1 & 3 & $\hat{\mathrm{Q}}=\overline{\mathrm{Q}}=1,15$ & - \\
& 4 & $\hat{\mathrm{Q}}=1,211-0,00613^{* *} \cdot \mathrm{T}+0,0000257^{*} \cdot \mathrm{T}^{2}-0,000000039^{*} \cdot \mathrm{T}^{3} 0,85$ \\
\hline 2 & 1 & $\hat{\mathrm{Q}}=1,638-0,00961^{* *} \cdot \mathrm{T}+0,0000297^{* *} \cdot \mathrm{T}^{2}-0,0000000406^{*} \cdot \mathrm{T}^{3}$ & 0,75 \\
2 & 2 & $\hat{\mathrm{Q}}=2,063-0,0108^{* *} \cdot \mathrm{T}+0,0000463^{* *} \cdot \mathrm{T}^{2}-0,0000000671^{*} \cdot \mathrm{T}^{3}$ & 0,74 \\
2 & 3 & $\hat{\mathrm{Q}}=1,633-0,00676^{* *} \cdot \mathrm{T}+0,0000262^{*} \cdot \mathrm{T}^{2}-0,0000000366^{*} \cdot \mathrm{T}^{3}$ & 0,82 \\
& & & \\
2 & 4 & $\hat{\mathrm{Q}}=1,728-0,00871^{* *} \cdot \mathrm{T}+0,0000385^{*} \cdot \mathrm{T}^{2}-0,0000000541^{*} \cdot \mathrm{T}^{3}$ & 0,71 \\
\hline 3 & 1 & $\hat{\mathrm{Q}}=\overline{\mathrm{Q}}=1,19$
\end{tabular}




\begin{tabular}{llll}
3 & 2 & $\hat{\mathrm{Q}}=\overline{\mathrm{Q}}=1,33$ & \\
3 & 3 & $\hat{\mathrm{Q}}=1,519-0,00179^{* *} \cdot \mathrm{T}$ & 0,70 \\
3 & 4 & $\hat{\mathrm{Q}}=1,68-0,00452^{* *} \cdot \mathrm{T}+0,000005823^{* *} \cdot \mathrm{T}^{2}$ & 0,86 \\
\hline 4 & 1 & $\hat{\mathrm{Q}}=\overline{\mathrm{Q}}=1,16$ & 0,69 \\
4 & 2 & $\hat{\mathrm{Q}}=1,995-0,00546^{* *} \cdot \mathrm{T}+0,00000745^{* *} \cdot \mathrm{T}^{2}$ & 0,69 \\
4 & 3 & $\hat{\mathrm{Q}}=1,61-0,0052^{* *} \cdot \mathrm{T}+0,00000857^{* *} \cdot \mathrm{T}^{2}$
\end{tabular}

Nota: TRAT - Tratamentos biológicos para a prevenção do entupimento; G - Gotejadores; T - Tempo de operação; * e ** Significativo a 5 e $1 \%$ de probabilidade, pelo teste "t", respectivamente.

No tratamento biológico TRAT 1 verificou-se que houve relação cúbica das subunidades gotejadoras com emissores G1 e G4 e quadrática da subunidade gotejadora com emissor $\mathrm{G} 2$ em relação às variáveis vazão $(\mathrm{Q})$ e tempo de operação (T), enquanto na subunidade gotejadora com emissor G3 a média foi a melhor representação para os dados de Q e T. Esses resultados diferem dos obtidos por Marques et al. (2016) com unidades gotejadoras que operaram com efluente de laticínios diluído durante $200 \mathrm{~h}$, onde os modelos de regressão linear e quadrático e a média foram a melhor representação para a relação entre Q e T.

Para o tratamento biológico TRAT 2, todas as subunidades gotejadoras apresentaram relação cúbica entre os dados de Q e T. Não corroborando com os resultados do trabalho de Fernandes et al. (2014) que obtiveram relações lineares e quadráticas entre os dados de Q e T em unidades gotejadoras que operaram com água residuária do processamento da castanha de caju durante $160 \mathrm{~h}$.

O tratamento biológico TRAT 3 apresentou relação linear da subunidade gotejadora com emissor G3 e quadrática da subunidade com emissor G4 em relação às variáveis $\mathrm{Q}$ e $\mathrm{T}$, entretanto a média foi o melhor ajuste entre os dados de $\mathrm{Q}$ e T para as unidades gotejadoras dotadas dos emissores G1 e G2. Esses resultados não 
corroboram com os do trabalho de Batista et al. (2014) que encontraram apenas relações lineares entre os dados de Q e T em unidades gotejadoras de aplicação de efluentes de suínos durante $160 \mathrm{~h}$.

Notou-se, no tratamento biológico TRAT 4, que houve relação quadrática entre os dados de Q e T nas unidades gotejadoras dotadas dos emissores G2 e G3, porém nas unidades gotejadoras com emissores G1 e G4 a média foi a melhor representação para os dados de Q e T. Esses resultados diferem dos obtidos por Batista et al. (2011), onde a regressão linear foi a que melhor se ajustou aos dados de Q em função de T em unidades gotejadoras de aplicação de água residuária sanitária preliminar, secundária e terciária durante $500 \mathrm{~h}$.

Constam, na Tabela 5, as equações de regressões lineares simples e múltiplas ajustadas à vazão dos emissores $(\mathrm{Q})$ em função da qualidade do esgoto sanitário tratado aplicado pelas subunidades gotejadoras, mediante aplicação de quatro tratamentos biológicos para a prevenção do entupimento.

Tabela 5. Equações de regressão ajustadas à vazão dos emissores G1, G2, G3 e G4 (Q) em função dos atributos físico-químicos e microbiológicos do esgoto sanitário tratado aplicado pelas subunidades gotejadoras, mediante aplicação de quatro tratamentos biológicos para a prevenção do entupimento (T1, T2, T3 e T4)

\begin{tabular}{c|c|l|c}
\hline \multicolumn{1}{c}{ TRAT } & G & \multicolumn{1}{l}{ Equação de regressão } & $\mathrm{R}^{2}$ \\
\hline 1 & 1 & $\hat{\mathrm{Q}}=2,490+1,423^{0} \cdot \mathrm{Fe}-0,000552^{* *} \cdot \mathrm{SD}$ & 0,91 \\
\hline 1 & 2 & $\hat{\mathrm{Q}}=3,559+2,184^{0} \cdot \mathrm{Fe}-0,000964^{* *} \cdot \mathrm{SD}$ & 0,94 \\
\hline 1 & 3 & $\hat{\mathrm{Q}}=2,82-0,00297^{* *} \cdot \mathrm{SS}$ & 0,85 \\
\hline 1 & 4 & $\hat{\mathrm{Q}}=2,97+0,517^{\circ} \cdot \mathrm{Fe}-0,00124^{*} \cdot \mathrm{SS}-0,000392^{*} \cdot \mathrm{SD}$ & 1,00 \\
\hline 2 & 1 & $\hat{\mathrm{Q}}=2,36+1,568^{*} \cdot \mathrm{Fe}-0,000513^{* *} \cdot \mathrm{SD}$ & 0,95 \\
\hline 2 & 2 & $\hat{\mathrm{Q}}=3,78-0,0008^{* *} \cdot \mathrm{SD}$ & 0,90 \\
\hline 2 & 3 & $\hat{\mathrm{Q}}=2,23+0,185^{*} \cdot \mathrm{Ca}+1,68^{*} \cdot \mathrm{Fe}-0,000613^{* *} \cdot \mathrm{SD}$ & 0,99 \\
\hline 2 & 4 & $\hat{\mathrm{Q}}=2,72+1,68^{\circ} \cdot \mathrm{Fe}-0,00065^{* *} \cdot \mathrm{SD}$ & 0,91 \\
\hline
\end{tabular}




\begin{tabular}{c|c|l|c}
\hline 3 & 1 & $\hat{\mathrm{Q}}=2,72+1,29^{\circ} \cdot \mathrm{Fe}-0,00328^{* *} . \mathrm{SS}$ & 0,97 \\
\hline 3 & 2 & $\hat{\mathrm{Q}}=9,88+1,49^{0} \cdot \mathrm{Fe}-0,00497^{* *} \cdot \mathrm{SS}-0,71^{*} \cdot \mathrm{pH}$ & 0,99 \\
\hline 3 & 3 & $\hat{\mathrm{Q}}=4,2+0,892^{*} \cdot \mathrm{Fe}-0,169^{*} \cdot \mathrm{pH}-0,00029^{* *} \cdot \mathrm{SD}-0,00163^{* *} \cdot \mathrm{SS}$ & 1,00 \\
\hline 3 & 4 & $\hat{\mathrm{Q}}=3,11+1,67^{*} \cdot \mathrm{Fe}-0,00426^{* *} \cdot \mathrm{SS}$ & 0,97 \\
\hline 4 & 1 & $\hat{\mathrm{Q}}=\overline{\mathrm{Q}}=14,25$ & $\cdot$ \\
\hline 4 & 2 & $\hat{\mathrm{Q}}=3,84+2,53^{0} \cdot \mathrm{Fe}-0,005537^{* *} \cdot \mathrm{SS}$ & 0,94 \\
\hline 4 & 3 & $\hat{\mathrm{Q}}=2,85-0,00447^{*} \cdot \mathrm{SS}+3,019^{\circ} \cdot \mathrm{Fe}$ & 0,87 \\
\hline 4 & 4 & $\hat{\mathrm{Q}}=9,13-0,000643^{*} \cdot \mathrm{SD}-0,794^{0} \cdot \mathrm{pH}+3,344^{0} \cdot \mathrm{Fe}$ & 0,91 \\
\hline
\end{tabular}

Nota: TRAT - Tratamentos biológicos para a prevenção do entupimento; G - Gotejadores; SS - Sólidos suspensos, SD - Sólidos dissolvidos, Ca - Cálcio, Fe - Ferro total, ${ }^{0},{ }^{*}$ e **Significativo a 10, 5 e 1 \% de probabilidade, pelo teste " $\mathrm{t}$ ", respectivamente.

Em relação ao tratamento biológico TRAT 1, notou-se que houve relações lineares entre os dados de vazão (Q) e os atributos Fe, SD e, ou SS, entretanto evidenciou-se que a redução nos valores de $\mathrm{Q}$ foi influenciada pelos atributos SD e, ou SS nas subunidade gotejadoras dotadas dos emissores G1, G2, G3 e G4. No tratamento biológico TRAT 2 ocorreram relações lineares entres os dados de Q e os atributos $\mathrm{Fe}, \mathrm{SD}$, SS e, ou $\mathrm{Ca}$, sendo SD o atributo que mais contribuiu com o processo de obstrução. Para o tratamento biológico TRAT 3 houve relação linear entre os dados de Q e os atributos Fe, SD, SS e, ou pH, porém SS, SD e, ou pH foram os atributos que mais interferiram no entupimento dos gotejadores. O tratamento biológico TRAT 4 apresentou relações lineares entre os dados de Q e os atributos $\mathrm{Fe}, \mathrm{SD}$, SS e, ou pH, no entanto as alterações de Q foram mais influenciadas pelos atributos SS, SD e, ou $\mathrm{pH}$.

Esses resultados diferem dos encontrados por Batista et al. (2008) em seu estudo com unidades gotejadoras que operaram por 560 com esgoto sanitário terciário, onde houve relações lineares entre os dados de Q e os atributos $\mathrm{Fe}, \mathrm{Mn}$, $\mathrm{SD}$ e $\mathrm{pH}$, sendo que Fe, $\mathrm{pH}$ e SD foram os atributos que mais contribuíram para o entupimento dos emissores. 


\section{CONCLUSÕES}

Houve interação entre as dosagens do catalizador enzimático, tipos de gotejadores e tempos de funcionamento estudados, no entanto o catalisador enzimático não preveniu a obstrução dos gotejadores em função da elevada concentração de cloreto no esgoto sanitário tratado.

Os modelos de regressão cúbico, quadrático e linear, foram os que melhor se ajustaram aos dados de vazão em função dos tempos de operação mediante tratamento biológico.

As análises de regressão linear múltipla revelaram que os atributos SD, SS $\mathrm{e} \mathrm{pH}$ foram os que mais interferiram no processo de entupimento dos gotejadores aplicando esgoto sanitário tratado.

\section{REFERÊNCIAS}

ALVARES, C. A.; STAPE, J. L.; SENTELHAS, P. C.; GONÇALVES, J. L. M.; SPAROVEK, G. Köppen's climate classification map for Brazil. Meteorologische Zeitschrift, v. 22, n. 6, p. $711-728,2013$.

BATISTA, R. O.; SOARES, A. A.; SOUZA, J. A. R.; BATISTA, R. O. Modelos empíricos da irrigação localizada com esgoto sanitário tratado. Engenharia na Agricultura, v. 16, n. 3, p. 369-377, 2008.

BATISTA, R. O.; SOARES, A. A.; MOREIRA, D. A.; FEITOSA, A. P.; BEZERRA, J. M. Influência de diferentes qualidades de esgoto doméstico na vazão de gotejadores. Revista Caatinga, v. 24, n. 3, p. 128-134, 2011.

BATISTA, R. O.; OLIVEIRA, R. A.; SANTOS, D. B.; OLIVEIRA, A. F. M.; AZEVEDO, C. A. V.; MEDEIROS, S. S. Obstrução e uniformidade de aplicação em sistemas de irrigação por gotejamento aplicando-se efluente da suinocultura. Revista Brasileira de Engenharia Agrícola e Ambiental, v. 17, n. 7, p. 698-705, 2013.

BATISTA, R. O.; OLIVEIRA, R. A.; FIGUEIREDO, V. B.; SILVA, K. B.; FERREIRA, D. C. Vazão de gotejadores com distintos tempos de irrigação aplicando água residuária 
de suinocultura e água de abastecimento. Engenharia Agrícola, v. 34, n. 6, p. 1283$1295,2014$.

BATISTA, R. O.; SILVA, K. B.; SILVA JÚNIOR, M. J.; SANTOS, D. B.; CUNHA, R. R.

Performance of drip emitters for different pressures and applicationof cashew nuts wastewater. Revista DYNA, v. 85, n. 204, p. 38-43, 2018.

COSTA, D. O.; BATISTA, R. O.; VALE, H. S. M.; SOUSA, A. B.; DOMBROSKI, S. A. G. Biological treatment of drippers clogged by the use of treated domestic wastewater. Revista Brasileira de Engenharia Agrícola e Ambiental. v. 20, n. 7, p. 595-599, 2016.

CUNHA, M. E.; MARQUES, B. C. D.; BATISTA, R. O.; COSTA, A. G.; CUNHA, R. R.; ANDRADE, A. T. S. Obstrução de gotejadores operando com efluente de laticínios diluído. Revista Brasileira de Agricultura Irrigada, v. 11, n. 4, p. 1517-1527, 2017.

FERNANDES, R. K. A.; BATISTA, R. O.; SILVA, S. K. C.; OLIVEIRA, J. F.; PAIVA, L. A. L. Vazão de gotejadores aplicando água residuária da castanha de caju. Irriga, Botucatu, v. 19, n. 4, p. 585-597, 2014.

JASIM, S. Y.; SATHTHASIVAM, J.; LOGANATHAN, K.; OGUNBIYI, O. O.; SARP, S. Reuse of Treated Sewage Effluent (TSE) in Qatar. Journal of Water Process Engineering, v. 11, n. 1, p. 174-182, 2016.

MARQUES, B. C. D.; CUNHA, V. T.; CUNHA, V. T.; SILVA, K. B.; BATISTA, R. O. Desempenho de gotejadores operando com água residuária de laticínios em escala laboratorial. Irriga, v. 21, n. 1, p. 140-155, 2016.

MESQUITA, F. O.; ALVES, S. M. C.; BATISTA, R. O.; DANTAS, T. B.; DI SOUZA, L. Desempenho de gotejadores aplicando percolado de aterro sanitário diluído. Irriga, v. 21, n. 1, p. 156-171, 2016 a.

MESQUITA, F. O.; ALVES, S. M. C.; BATISTA, R. O.; DANTAS, T. B.; DI SOUZA, L. Drip units operating with dilute landfill leachate. Revista Caatinga, v. 29, n. 1, p. 163172, 2016b.

PIMENTEL-GOMES, F. Curso de estatística experimental. 15. ed. Piracicaba, 
FEALQ, 2009. 451p.

RIBEIRO JÚNIOR, J. I.; MELO, A. L. P. Guia prático para utilização do SAEG. Viçosa: UFV, 288p, 2008.

RICE, E. W.; BAIRD, R. B.; CLESCERI, A. D. Standard methods for the examination of water and wastewater. 22 ${ }^{\mathrm{a}}$ ed. Washington: APHA, AWWA, WPCR, 1496p, 2012.

SILVA, K. B.; BATISTA, R. O.; MESQUITA, F. O.; COELHO, D. C. L.; SANTOS, W. O. Empirical models for performance of drippers applying cashew nut processing wastewater. Revista Caatinga, v. 29, n. 2, p. 405-414, 2016.

SONG, P.; LI, Y.; ZHOU, B.; ZHOU, C.; ZHANG, Z.; LI, J. Controlling mechanism of chlorination on emitter bio-clogging for drip irrigation using reclaimed water. Agricultural Water Management, v. 184, n. 1, p. 36-45, 2017.

ZHOU, B.; WANG, T.; LI, Y.; BRALTS, V. Effects of microbial community variation on bio-clogging in drip irrigation emitters using reclaimed water. Agricultural Water Management, v. 194, n. 1, p. 139-149, 2017.

Recebido em: 18/08/2017 Aceito em: 06/06/2018 